RELACult - Revista Latino-Americana de Estudos em Cultura e Sociedade e-ISSN 2016/Atual: 2525-7870 | e-ISSN 2015/2016: 2447-018X

\title{
Impacto do desenvolvimento do agronegócio nas economias periféricas de Brasil e Paraguai
}

\author{
Impacto en el desarrollo agroindustrial en las economías periféricas de
} Brasil y Paraguay

Impact of agribusiness development on the peripheric economies of Brazil and Paraguay

\author{
Fabio Silvestre Cardoso ${ }^{1}$ \\ Luciana Pelaes Rossetto ${ }^{2}$
}

\begin{abstract}
Resumo
O artigo trata da inserção do Brasil e do Paraguai no contexto internacional na condição de países periféricos em função da dependência econômica da produção de commodities. A partir de revisão de literatura e de análise de relatórios econômicos, contextualiza-se o peso do setor agrícola no PIB de cada país e analisa-se o desempenho de ambos na atual dinâmica da globalização, aprofundando a discussão com as questões relativas ao embate centroperiferia. Por fim, verifica-se que Brasil e Paraguai são dependentes do cenário mundial, regido pelos países que controlam o capitalismo internacional, portanto na condição de periféricos e sem perspectivas de mudança.
\end{abstract}

Palavras-Chave: agronegócio, Brasil, economia, Paraguai, relação centro-periferia.

\section{Resumen}

Este texto trata de la inserción de Brasil y Paraguay en el contexto internacional sobre la condición de los países periféricos debido a la dependencia económica de la producción de commodities. A partir de la revisión y análisis de los informes económicos literatura, este texto contextualiza el peso del sector agrícola en el PIB de cada país y analiza el rendimiento tanto en la dinámica actual de la globalización, la profundización de la discusión de las cuestiones relativas de la colisión centro-periferia. Por último, se presenta como Brasil y Paraguay son dependientes de la escena mundial, que se rige por los países que controlan el capitalismo internacional, por lo tanto, en una condición periférica y sin perspectivas de cambio.

Palabras claves: agroindustria, Brasil, economía, Paraguay, relaciones centro-periferia.

\begin{abstract}
This paper is about the international insertion of Brazil and Paraguay in the condition of peripheric countries caused by the economic dependence of the production of commodities. From review of literature and analysis of economic reports, the weight of the agricultural sector is contextualized in GDP of each country and their performance is analyzed in the current dynamics of globalization, considering the discussion with the questions related to the center-periphery connexion. At last, Brazil and Paraguay are dependent on the world scenario, governed by countries that control international capitalism, consequently in the condition of periphery and without prospects of change.
\end{abstract}

Keywords: agribusiness, Brazil, economy, Paraguay, center-periphery connexion.

\footnotetext{
${ }^{1}$ Doutorando do Programa de Integração da América Latina, da Universidade de São Paulo (USP); São Paulo, SP, Brasil. E-mail: fabioscardoso@usp.br.

${ }^{2}$ Doutoranda do Programa de Integração da América Latina, da Universidade de São Paulo (USP); São Paulo, SP, Brasil. E-mail: lucianarossetto@usp.br.
} 


\section{Introdução}

A economia paraguaia é baseada no setor agropecuário, principalmente voltado à produção e à exportação de commodities. A industrialização é mínima, composta sobretudo por empresas de maquila, e o país hoje se consolidou como reexportador de produtos previamente importados de países industrializados aos seus vizinhos do Mercosul - em um processo conhecido como triangulação. Portanto, o desempenho de sua economia é profundamente dependente do comportamento do preço das commodities no mercado internacional e da estabilidade de outras economias mundiais.

Enquanto em meados do século passado outros países da América Latina adotavam medidas para tentar desenvolver a indústria, como o Processo de Substituição de Importações (PSI), o Paraguai manteve sua economia aberta e não protecionista. Apesar de a política econômica registrar números positivos nos últimos anos, o país enfrenta graves problemas sociais ocasionados pela concentração de renda. As baixas tarifas de impostos não são eficientes para atrair implantação significativa de indústrias e ainda impossibilitam que a União tenha arrecadação suficiente para investir em outros setores.

Já a economia brasileira é bem mais diversificada, até em função do tamanho do país, ainda que o setor agrícola tenha um peso vultoso nos dados do Produto Interno Bruto (PIB). Mesmo não tendo uma industrialização significativa para concorrer com economias mais desenvolvidas, bens duráveis e produtos de consumo interno de uso cotidiano ou de baixa tecnologia - sem valor agregado - são comumente produzidos no próprio país. Ao contrário do Paraguai, o Brasil tem fortes restrições à entrada de artigos importados, fixando alta carga tributária, que torna desinteressante a entrada desses produtos, ainda que se permita a importação de praticamente qualquer item.

Além disso, é importante lembrar que Brasil e Paraguai pertencem ao Mercosul, união aduaneira que tem por objetivo fomentar nos países membros a circulação de bens, serviços e fatores produtivos, bem como estabelecer uma política comercial comum. Nesse sentido, os dois países estão em concordância com o aspecto da globalização contemporânea, processo que teve desenvolvimento largo na ordem internacional a partir dos anos 1990. Em linhas gerais, esse fator deveria fazer com que Brasil e Paraguai participassem do cenário da globalização e de suas consequências, desfrutando das vantagens comparativas, de modo mais pleno. Todavia, o fato de serem países periféricos na conjuntura internacional faz com que essas nações estejam à margem desse processo de integração. Brasil e Paraguai se estabelecem como países frágeis para a forma agressiva com que se apresenta a globalização contemporânea. 
Com base no exposto, este artigo tem como objetivo identificar como a condição periférica de Brasil e Paraguai no contexto internacional é forjada graças às suas características de exportadores de commodities. Ademais, busca analisar como a conjuntura favorável da economia global antes da crise e a forte demanda de commodities melhoraram as respectivas performances comerciais dos países, fazendo com que essas nações ficassem ainda mais dependentes da exportação de matéria-prima num momento em que os países centrais se distanciam das nações periféricas graças ao desempenho da indústria de transformação e à agenda de inovação, condenando, com isso, Brasil e Paraguai a uma condição periférica a longo prazo.

O texto está dividido em quatro segmentos. No primeiro, a partir de revisão de literatura, expõe-se a situação das economias do Brasil e do Paraguai. Em seguida, contextualiza-se o peso do setor agrícola na formação do Produto Interno Bruto (PIB) de cada país a partir da análise de relatórios econômicos. A terceira aborda como a questão centroperiferia é um fator decisivo para as condições econômicas e para a performance desses países conforme a dinâmica da globalização. Por fim, à guisa de conclusão, busca-se uma resposta acerca de qual deve ser a posição desses países no tocante à política comercial conforme o estado de coisas da globalização contemporânea. Apesar da grande arrecadação em termos financeiros, a riqueza oriunda do setor agrícola paraguaio permanece concentrada nos proprietários de grandes latifúndios, enquanto a maioria da população do campo nos dois países vive em situação de pobreza ou pobreza extrema. Grosso modo, algo semelhante pode ser dito a respeito do Brasil, país onde a reforma agrária sempre foi motivo de disputa política entre os proprietários de terra e a fatia majoritária da população que vive em condições precárias no campo.

\section{Panorama econômico}

Para entender o atual momento econômico de Brasil e Paraguai, países onde a oposição capital-trabalho tem se acirrado nos últimos anos, faz-se necessário traçar breve um panorama das principais transformações econômicas pelas quais passaram ambos os países ao longo do século XX.

De modo a protegerem-se da crise na economia mundial ocorrida nos anos 1930, grande parte dos países da América Latina adotou um modelo de desenvolvimento baseado no PSI, o Processo de Substituição de Importações na expressão cunhada pela economista Maria da Conceição Tavares (2000, p. 225). Como consequência da restrição das importações, em meados do século XX, os países passaram a promover o crescimento industrial com objetivo 
de produzir, por substituição, dentro de suas fronteiras, os produtos antes importados para atender a totalidade da demanda interna (TAVARES, 2000, p. 223). Em outras palavras, para a maioria dos governos latino-americanos, o foco da economia passou a ser a produção/industrialização interna em detrimento do setor primário agrícola voltado à exportação. Esse modelo foi aplicado entre 1930 e 1990 no Brasil, quando foi substituído pelo atual modelo neoliberal.

No Brasil, segundo Tavares (2000, p. 227), a substituição das importações abarcou bens não duráveis e alastrou-se até ao estrato dos bens de capital. Em relação a estes, por exemplo, o governo brasileiro viabilizou os recursos para investimento, com a constituição de estatais nas áreas de metalurgia, petroquímica, siderurgia, além de financiamento para setores como cimento e papel. A partir da década de 1950, o governo também passou a investir na infraestrutura para viabilizar o escoamento da produção, especialmente financiando iniciativas nas áreas de energia e de transporte, que exigem um grande volume de capital e possuem longo prazo de maturação.

O Brasil, nas décadas de 1960 e 1970, passa por uma política de estímulo às exportações, com desvalorização cambial, incentivos fiscais, consolidação da Zona Franca em Manaus, e investimentos públicos para viabilizar as exportações. No entanto, houve um crescimento da fronteira agrícola com incentivos governamentais para explorar a região Centro-Oeste do país, principalmente, como explica Silva (1998, p. 29):

(...) na década de 60 , particularmente em seus anos finais, havia um conjunto de condições macroeconômicas e políticas internas que possibilitaram uma mudança qualitativa no padrão de desenvolvimento da agricultura e no lugar que ela passava a ocupar no padrão geral de acumulação do país. Essa mudança qualitativa concretizouse nos complexos agroindustriais e no processo de fusão/integração de capitais intersetoriais pelo capital financeiro. (SILVA, 1998, p.29)

Em relação à industrialização, o Brasil prosperou até certo patamar por conta das medidas protecionistas, que proibiam ou sobretaxavam as importações. O objetivo era garantir espaço para a produção nacional. Um dos problemas do PSI no Brasil é que, com a indústria protegida, não houve preocupação com o preço e a qualidade dos produtos. Com a abertura do mercado na década de 1990, sem conseguir competir com produtos mais baratos e eficientes, o processo de industrialização é estancado. Desde então, com a elevação do preço das commodities no mercado mundial, o Brasil volta-se ao setor primário, tornando-se um dos maiores exportadores de grãos e minérios. 
No Brasil, o processo de abertura de mercados está em linha com o desenvolvimento de uma abordagem mais ampla em relação à América Latina, a saber: o Consenso de Washington, agregando, em princípio, os interesses de entidades como Banco Mundial e Fundo Monetário Internacional. Embora não representassem necessariamente o credo de uma agenda neoliberal, desde então, o Consenso de Washington passou a simbolizar medidas associadas à manutenção do poder das nações mais desenvolvidas em detrimento do desempenho autônomo dos países periféricos.

No caso do Brasil em particular, essa mudança tem um impacto bastante significativo, uma vez que o país, em meados do século XX, alterou sua política econômica, tendo como base o PSI, com o Brasil passando a investir na indústria e não apenas em commodities. Como consequência da crise econômica de 1929, o governo Vargas se viu diante da necessidade de estabelecer "medidas de controle do comércio externo, das taxas de câmbio e de compra dos excedentes exportáveis, na tentativa de impedir a redução da renda interna", conforme analisa Maria José Oliveira Lima (2009). Ainda de acordo com a autora, é possível compreender o funcionamento da estrutura básica do capitalismo brasileiro quando se toma como referência o desenvolvimento da indústria no Brasil a partir dos anos 1930. Nas palavras da autora:

A estrutura básica do capitalismo brasileiro está constituída pela empresa estatal, pela empresa estrangeira e pela empresa nacional. Essas empresas tiveram o início de seu desenvolvimento nos anos 1930 e se consolidaram entre 1950 e 1970. A partir da década de 1990, diante das políticas de ajuste neoliberal direcionado ao processo de privatização das empresas nacionais, a empresa estatal passou a desaparecer. (LIMA, 2009, p.22)

Contudo, enquanto as economias da América Latina implantavam medidas que tinham como objetivo a industrialização em meados do século XX, o Paraguai manteve como atividade principal de sua economia a exploração agrícola. É fundamental ressaltar que o país vivia uma situação de instabilidade política e econômica no período, envolvendo-se em uma disputa territorial com a Bolívia (Guerra do Chaco, 1932-1935), seguida por uma guerra civil (1947), ambas dispendiosas em termos financeiros e humanos. A relativa estabilidade política, mas não econômica, teve início com a tomada do poder pelo ditador Alfredo Stroessner (1954-1989).

Para tentar baixar os altos índices inflacionários ainda na década de 1950, Stroessner recorreu a empréstimos do Fundo Monetário Internacional, que impôs duras medidas recessivas de estabilização, entre elas a diminuição das tarifas de importação/exportação, segundo Hanratty e Meditz (1990, p. 102). 
Unlike many other Latin American governments, which followed an importsubstitution industrial policy, the Paraguayan government had played a minimalist role in the economy through most of the postwar era, curtailing import tariffs and maintaining a realistic exchange rate. (HANRATTY e MEDITZ, 1990, p. 138).

Somente na década de 1970, com a implantação da Usina Hidrelétrica de Itaipu, o investimento em obras públicas, como rodovias, e a expansão da fronteira agrícola na região leste com a chegada ao campo de imigrantes brasileiros, "os brasiguaios", é que o Paraguai experimentou um crescimento econômico mais notável, que já havia se sucedido em países contíguos.

Segundo Hanratty e Meditz (1990, p. 99), a economia paraguaia estagnou nos anos 1980 em função de nova crise mundial, do término das obras de Itaipu - o que diminuiu os investimentos na infraestrutura, e da queda no preço das commodities. Os autores ressaltam ainda que o país sempre manteve baixas as tarifas de importação e os impostos sobre renda de pessoa física e jurídica.

Borda e Masi (2002, p. 200) ratificam que os baixos índices de crescimento econômico no Paraguai nas décadas de 1980 e 1990 foram reflexos da queda nos preços internacionais do algodão e da soja. Houve contração econômica no período, o que já mostrava o esgotamento do modelo produtivo agrário, trazendo desemprego e forçando deslocamentos internos da população, além do aumento da economia informal.

No entanto, Borda e Masi (2002, p. 193) explicam que o Paraguai nunca sofreu com o descontrole dos índices de inflação, caso do Brasil na década de 1980, por exemplo. Segundo os autores, a inflação nos anos 1970 teve uma média anual de $11,1 \%$, chegando à média de 20,8\% ao ano na década de 1980 e retornando a 15,7\% ao ano durante a década de 1990.

Com a criação do Mercosul, em 1991, foram implantados incentivos fiscais como a Ley de Maquila e a Ley de Zonas Francas, em uma tentativa de promover o estabelecimento de empresas de exportação, voltadas para a montagem do produto final, com exoneração de impostos internos e de tarifas aduaneiras (ARCE, 2010, p. 121). No entanto, apesar dos incentivos fiscais e baixos impostos para atrair empresas, o grau de industrialização não avançou significativamente. $\mathrm{O}$ governo nunca conseguiu colocar em prática uma estratégia deveras eficiente para o desenvolvimento econômico, tendo infraestrutura e serviços públicos precários, suscitando um custo desmesurado de logística.

De acordo com Arce (2010, p. 121), a reexportação de produtos industrializados, chamada triangulação comercial, foi também um fator que prejudicou o desenvolvimento da indústria paraguaia. 
De acordo com dados de 2016 do Heritage Foundation ${ }^{3}$, apesar de tarifas baixas e isenções relativamente benéficas às empresas, há muitos problemas em outras áreas, como a qualidade da infraestrutura rodoviária do país. O levantamento ainda ressalta a falta de eficiência e independência política do sistema judiciário paraguaio.

O comércio ilegal também subsiste no fluxo comercial do Paraguai mesmo nos dias atuais. Nas décadas de 1970 até meados dos anos 1980 havia uma importação ilegal de itens produzidos no Brasil e na Argentina, que eram consumidos pela população local ou reexportados pelo Paraguai. Porém, em meados da década de 1980, houve uma inversão nesse sentido, quando o Paraguai passou a importar produtos dos Estados Unidos e da Ásia, para exportá-los especialmente ao Brasil e à Argentina, que tinham altas tarifas aduaneiras, e nem sempre pelas vias legais (BORDA e MASI, 2002, p. 230).

A Ciudad del Este, na fronteira com o Brasil, é tida como o "símbolo" desse comércio. Desde sua fundação durante a ditadura de Stroessner, em fevereiro de 1957, Ciudad del Este foi pensada para ser um "hubby" comercial na região, afirma Schuster (2015, p. 42). Hoje, porém, tornou-se um gargalo não apenas para o comércio legal de importados, mas também para o contrabando.

No entanto, de acordo com Schuster (2015, p. 42), a própria política de livre mercado do Paraguai já foi estabelecida beneficiando o setor mais rico da sociedade, que se tornou proprietário das lojas e distribuidoras, deixando para a população trabalhadora apenas o fornecimento de mão-de-obra barata para a exploração da atividade.

\section{Setor agrícola no PIB dos países}

Em 2015, o Paraguai registrou um crescimento de 3\% no PIB, superior à média da América Latina, informa o Estudio Económico de América Latina y el Caribe - 2016, elaborado pela Cepal (2016, p. 1). Esse crescimento é baseado na agricultura, com a exportação de algodão, carne, milho e, principalmente, de soja. De acordo com o relatório da Cepal (2016, p. 4), a agricultura é o maior componente do PIB paraguaio, representando cerca de $20 \%$, e teve um crescimento acumulado de 6,3\% em 2015.

Com território de $406.752 \mathrm{~km}^{2}$, pouco maior que o estado brasileiro de Mato Grosso do Sul, o Paraguai é o quarto maior exportador e o sexto maior produtor de soja do mundo, conforme dados do USDA (2016a, p.13). Na safra 2015/2016, o Paraguai exportou 5,3 milhões de toneladas, mesma previsão para a colheita de 2016/2017. Ainda segundo o USDA, a soja

\footnotetext{
${ }^{3}$ Cf. índice de liberdade econômica, disponível em <http://www.heritage.org/index/country/paraguay>. Acesso em 29 jan. 2017
} 
paraguaia é exportada preponderantemente através dos portos de Rosario, na Argentina, e Nueva Palmira, no Uruguai, para países da União Europeia e para a Rússia, os principais compradores desses grãos do Paraguai. Cabe ressaltar, todavia, que apesar de Rússia e União Europeia serem os preeminentes compradores de soja, os países do Mercosul são os maiores parceiros comerciais do Paraguai e destino de grande parte de suas exportações - inclusive na compra de soja por Brasil, Uruguai e Argentina (USDA, 2016b, p. 4)

Conforme a Cepal (2016, p. 4), o crescimento do PIB paraguaio em 2015 foi resultado de um melhor desempenho na produção de outros produtos agrícolas, como milho, arroz e trigo. Já a pecuária teve uma contração de $1,3 \%$ por causa da diminuição do volume de exportação para a Rússia.

O peso do setor agropecuário no PIB do Paraguai fica explícito também ao analisarmos o desempenho do PIB setorial nos últimos anos. Como mostra o relatório da Cepal (2016, p. 7), entre 2007 e 2015 o PIB total ficou negativo sempre que ocorreu contração no setor: em 2009, quando o PIB total diminuiu 4\%, o PIB setorial teve queda de 17,3\%; e 2012, quando o PIB total retraiu 1,2\%, o PIB setorial teve diminuição de 19,8\%. Em 2013, quando o setor agropecuário teve crescimento de 41,2\%, em parte devido à recuperação do ano anterior, o PIB total do Paraguai cresceu 14\%. Mesmo fenômeno é observado em 2010, com a recuperação do PIB setorial que registrou crescimento de $34,2 \%$, o PIB total paraguaio registrou crescimento de $13,1 \%$.

De acordo com o Centro de Análisis y Difusión de la Economía Paraguaya (Cadep), em 2015, as exportações totais alcançaram US\$ 8,8 bilhões. Um percentual de $71 \%$ (pouco mais de US\$ 6,2 bilhões) correspondem a produtos originários do Paraguai, provenientes sobretudo do setor primário, e 29\% (pouco mais de US\$ 2,5 bilhões) correspondem à exportação de "produtos de reexportação", que são importados pelo Paraguai majoritariamente de países asiáticos e revendidos aos associados do Mercosul, especialmente ao Brasil. (CADEP, 2015, p. 3).

O relatório da Cepal indica que nos últimos anos a inflação também se mantém controlada. Em 2015, a taxa de inflação anual alcançou 3,1\% (2016, p.1). Ainda de acordo com a Cepal (2016, p. 2), desde 2011, o Banco Central do Paraguai usa a Taxa de Política Monetária (TPM) para controlar a inflação e cumprir as metas estabelecidas dentro de um determinado período. A meta de 2015 foi de 4,5\%, portanto o índice de inflação de 3,1\% ficou abaixo da expectativa do governo paraguaio.

Conforme o relatório da Cepal (2016, p. 5), o baixo índice de inflação teve origem na redução de preços de alimentos, que compensou o aumento dos preços de bens e serviços. 
Houve também queda no valor dos combustíveis, seguindo a queda dos preços internacionais. O Paraguai fechou o ano de 2015 com um déficit fiscal de 1,8\% do PIB, superando o máximo de 1,5\% de déficit estabelecido pela Ley de Responsabilidad Fiscal (CEPAL, 2016, p. 3). Em dezembro de 2015, as reservas internacionais registravam 6,2 bilhões de dólares. Esse nível de reservas permite cobrir 7,5 meses de importações e equivale a 1,5 vezes a dívida pública externa.

Já o Brasil teve uma diminuição de 3,8\% do PIB em 2015, com um aumento na taxa de desemprego que chegou a 11,2\% no segundo trimestre de 2016, informa o relatório da Cepal (2016a, p. 1). No PIB setorial, somente a agropecuária e a exploração de minas tiveram desempenho positivo em 2015, crescendo 1,8\% e 4,9\%, respectivamente (CEPAL, 2016a, p. 7). Com exceção de 2012 e 2009, onde ocorreu retração de $-3,1 \%$ e $-3,7 \%$, o PIB do setor agrícola manteve-se positivo, com destaque para 2013, onde se registrou aumento de $8,4 \%$ - o maior desde 2007, conforme a Cepal.

O Brasil é o maior exportador de soja e o segundo maior produtor do grão no mundo, atrás somente dos Estados Unidos (USDA, p. 13). O país exportou 58 milhões de toneladas de soja na safra 2016/2017, número recorde devido ao aumento da demanda chinesa, que comprou $75 \%$ da produção, e da norte-americana, que comprou 10\%, segundo a USDA (2017, p. 2). Porém, a Cepal (2016a, p. 4), aponta que em 2015 o comércio exterior brasileiro caiu 20\%, tanto em relação a exportações (-15,3\%) quanto a importações (-25,3\%). Isso ocorre porque os maiores compradores de produtos brasileiros, como China, Mercosul, União Europeia e Estados Unidos diminuíram o volume de compras.

\section{Pobreza no campo}

Conforme dados do Banco Mundial, o Paraguai registrou coeficiente de Gini de 51,67 em 2014, e o Brasil registrou 51,5. O coeficiente de Gini mede a desigualdade na distribuição da renda, em que 0 é a igualdade perfeita e 100 é a maior desigualdade. De acordo com a Organização das Nações Unidas (ONU), o Paraguai ocupa a $112^{\mathrm{a}}$ posição no Índice de Desenvolvimento Humano (IDH), com indicador de 0.679. Já o Brasil ocupa a $75^{\text {a }}$ posição.

O salário mínimo no Paraguai é de 1.824 .055 guaranis (US\$ 318). Segundo levantamento da Dirección General de Estadística, Encuestas y Censos (2015, p. 19), 33,57\% da população ocupada assalariada recebem menos de 1 salário mínimo ao mês e 29,60\% recebem de 1 a 1,5 salário mínimo. A taxa de desemprego foi de 5,3\% em 2015.

O salário mínimo no Brasil é de 880 reais (US\$ 279). Segundo dados do Instituto Brasileiro de Geografia e Estatística (IBGE), em janeiro de 2016 havia 14,9\% da população 
ocupada assalariada recebendo menos de 1 salário mínimo ao mês. A taxa de desemprego ficou em $11,6 \%$ em 2016.

O Paraguai investe pouco em educação, o que faz com que não tenha mão de obra especializada e atrapalhe a formação de indústrias. De acordo com dados da Unesco, foram investidos 3,55\% do PIB em educação em 2007. O número saltou para 4,96\% do PIB em 2012, mas os números ainda são menores do que os investidos por outros países da América Latina, como a Bolívia e o Brasil, que investiram em 2012, respectivamente, 6,43\% e 5,91\% do PIB em educação, ainda segundo a Unesco.

Alcaraz (2009, p. 176) informa que escolaridade média dos paraguaios moradores da zona rural é de quatro anos. O autor ainda afirma que quatro de cada dez pobres na zona rural nunca tiveram acesso à escolaridade. Fogel (2005, p. 35) ressalta que, na medida em que se aumenta a produtividade da soja com substituição da mão de obra por tecnologia de maquinário agrícola, os empregos na zona rural diminuem.

O relatório da Dirección General de Estadística, Encuestas y Censos de 2011 indica que 14,4\% da população paraguaia vivem na pobreza, obtendo rendimento mensal de até 438.954,00 guaranis (cerca de US\$ 75) - trabalhadores com ganhos acima deste valor são classificados como não pobres ${ }^{4}$. Outros $18 \%$ da população vivem na pobreza extrema, com até 284.088,00 guaranis ao mês (cerca de U\$ 49). A pobreza e a pobreza extrema estão concentradas justamente na zona rural paraguaia. Do total de 2.641.284 habitantes da zona rural, conforme os dados de 2011, 15,2\% são considerados pobres e 29,6\% vivem na pobreza extrema, o que totaliza $44,8 \%$ da população rural nessas condições.

No Brasil, dados do Ipea ${ }^{5}$ de 2014 indicam que 13,29\% da população brasileira tinha renda inferior à linha da pobreza e outros 4,20\% eram considerados pobres extremos. No Brasil, a incidência da extrema pobreza no meio rural é de $25,5 \%$.

De acordo com Alcaraz (2009, p. 177), a situação da pobreza na zona rural do Paraguai vincula-se ao acesso à terra e aos empecilhos que o trabalhador rural enfrenta para permanecer na área que lhe foi atribuída em programas de reforma agrária. Ainda que reconheça a facilidade maior para que essa população obtenha alimentos no campo, com lavouras de subsistência, Alcaraz (2009, p. 178) alega que população rural não encontra acesso a outros serviços públicos igualmente importantes. Sem apoio técnico, financeiro e até de instrução, relegados muitas vezes à própria sorte, só encontram saída na venda ou arrendamento de seus lotes a grandes

\footnotetext{
${ }^{4} \mathrm{O}$ Banco Mundial estabelece a linha internacional de pobreza de US\$ 3,10/dia

${ }^{5}$ Cf. dados do IPEA, disponível em < http://www.ipeadata.gov.br/Default.aspx>. Acesso em 30 jan. 2017.
} 
produtores. Acabam migrando para os centros urbanos, onde formam uma grande massa de excluídos.

Prado Junior (p. 156) explica a pobreza rural brasileira ao relacionar os grandes latifúndios e os trabalhadores de baixos salários e escolaridade. Essa população igualmente enfrenta embaraços no acesso a serviços públicos.

Toda a estrutura do país, toda sua organização se constitui no passado e ainda se orienta sobretudo no sentido de satisfazer às exigências da grande lavoura monocultural de tipo colonial, na base de que se formou e evoluiu a economia brasileira. (Prado Júnior, 1981, p. 193).

\section{Relação centro-periferia}

Em que pesem os últimos avanços de Brasil e Paraguai, existe uma espécie de denominador comum para esses dois países, a despeito do fato de pertencerem à mesma região (América do Sul) e também ao mesmo bloco econômico (Mercosul). Dito de outra maneira, Brasil e Paraguai pertencem a uma condição geopolítica que pode ser denominada como periférica. É correto assinalar que essa condição, a de país periférico, não se aplica exclusivamente às nações citadas acima neste parágrafo; antes, trata-se de um aspecto da conjuntura da política internacional, tal qual foi forjada pelos principais atores da estrutura de poder mundial. Nesse sentido, convém discutir, primeiro, o que significa o conceito de periferia aqui adotado e, segundo, como é que esse conceito captura o contexto de Brasil e Paraguai.

De início, o conceito. Ao longo do século XX, o termo periferia foi utilizado em inúmeras ocasiões e com propósitos distintos. Não apenas no que tange à localização geográfica e espacial, mas também com um sentido político repleto de significado. No que concerne à discussão que ora está sendo elaborada neste artigo, vale a pena citar o trabalho de Celso Furtado, que, no livro A fantasia organizada reconstitui o momento em que esse termo ganhou força junto aos trabalhos da CEPAL. É o que se lê no texto O Manifesto dos Periféricos, onde o autor recupera em detalhe como aquela construção teórica foi forjada. Embora não seja um livro necessariamente de economia, o comentário de Furtado destaca aspectos importantes a respeito da dinâmica entre os países centrais e as nações periféricas, como o economista Raul Prebisch, alçado à condição de autoridade nessa discussão (afinal, foi o texto de Prebisch que arregimentou o debate), bem como as características mais elementares dos países periféricos em relação aos países centrais. De acordo com as palavras de Celso Furtado: 
americanos, estávamos longe de ter uma "correta interpretação teórica" da realidade, mas já sabíamos que para obtê-la necessitávamos abandonar a "ótica dos centros mundiais". Com um claro gesto na direção da nova geração, assinalava a carência de economistas capazes de penetrar com critério original os fenômenos concretos latinoamericanos". E acrescentava enfático que não bastava enviá-los às universidades da Europa e dos Estados Unidos, pois "uma das falhas mais sérias de que padece a teoria econômica geral, contemplada pela periferia, é seu falso sentido de universalidade" (FURTADO, 2014, p.65)

Mais adiante, Furtado aponta para aquela que pode ser entendida como a linha mestra da crítica que faz à teoria das vantagens comparativas. E não para por aí. Para o autor, existia efetivamente um sentido à crítica da dinâmica internacional tal qual pautada pelo ideário dos países centrais. Em termos de competitividade, as nações periféricas não tinham meios de se equiparar às nações mais desenvolvidas, de modo que se estabelecia assim uma relação de perversa desigualdade. Desse modo, argumenta Furtado, o texto $O$ Desenvolvimento da América Latina e seus principais problemas, assinado por Raul Prebisch e com tradução para o português de Celso Furtado, foi publicado pela "Revista Brasileira de Economia" em 1949. O texto foi o "manifesto fundador da escola cepalina", de acordo com Furtado, que ainda registrou o seguinte:

\footnotetext{
O que dava importância ao novo documento era seu tom de denúncia de uma situação intolerável a que eram condenados os países exportadores de produtos primários. Graças à mudança de enfoque, o debate parecia mais próximo da realidade, e o espaço de manobra deixado aos países latino-americanos, maior. O comércio exterior é bom, não porque permite maximizar vantagens comparativas, mas porque nos fornece meios de pagamento para importar equipamentos, diversificar as estruturas produtivas, assimilar técnicas modernas. O sistema tradicional de divisão internacional do trabalho opera implacavelmente no sentido de criar servidões para os países de periferia. (FURTADO, 2014, p.67)
}

Ainda que não faça alusão direta à abordagem de Furtado, no livro A insubordinação fundadora, o autor Marcelo Gullo propõe uma reflexão pertinente a respeito da importância da condição periférica para o destino dos países enquanto atores na conjuntura internacional. De acordo com a análise de Gullo, aos países periféricos está destinado o papel de "objetos" enquanto as nações centrais são sujeitos da política internacional. Gullo observa que, ao mesmo tempo em que as nações hoje centrais adotaram estratégias, tais como o protecionismo e o impulso estatal, que são condenadas pela propaganda ideológica de quem está no poder, as nações periféricas são amplamente criticadas se, eventualmente, optarem por adotar uma estratégia que busque tensionar a situação de quem está no centro do sistema internacional.

Essa conjuntura que condena à periferia os países que não fazem parte dessa estrutura de poder tem como referência uma gramática que articula a teoria das relações internacionais 
com o ideário liberal. Em relação à teoria das relações internacionais, como destaca Gullo, embora exista o entendimento acerca da "igualdade jurídica dos Estados", uma simples leitura objetiva do contexto internacional é suficiente para mostrar que: "Os Estados não são iguais uns aos outros, simplesmente porque alguns têm mais poder do que outros”. Já em relação ao ideário liberal, convém observar que, conforme aponta Aníbal Quijano no ensaio Colonialidad del poder: eurocentrismo y América Latina, existe toda uma situação de controle do trabalho que determinou a distribuição geográfica de cada uma das formas integradas no capitalismo mundial.

Como antídoto para superar essa condição, Marcelo Gullo defende que esses países busquem um novo status, pautando-se por atender, em primeiro plano seus próprios interesses e, nessa direção, rebelando-se contra a estrutura perversa que mantém os países periféricos numa posição marginal do sistema. No caso específico de Brasil e Paraguai, isso se dá a partir da superação de uma estratégia voltada tão somente à produção de commodities.

Bem entendido está que, nos anos 2000, o alto desempenho da América Latina esteve associado ao bom momento do comércio de matéria-prima. Com base nessa performance, países da América do Sul puderam reestabelecer programas de distribuição de renda e articular uma nova frente de liderança global, sobretudo a partir do G20. Ocorre que é exatamente a manutenção desse status quo que permite uma espécie de refluxo desse avanço econômico. Num momento de queda do preço das commodities ou de retomada de uma agenda protecionista pelos países centrais, conjuntura que não está descartada depois do Brexit e da ascensão de Donald Trump à presidência dos Estados Unidos, são exatamente os países periféricos que acusam queda de rendimento.

Em comparação com os números de 2010 a 2012, o desempenho brasileiro de $2015^{6}$ sofreu um abalo significativo devido à queda do preço da soja e do trigo, por exemplo. Fosse um país não tão dependente das commodities, a vulnerabilidade em relação à crise não seria tão grande. Tivesse mais autonomia no tocante à conjuntura internacional, e o posicionamento do Brasil nessa dinâmica não seria a de nação periférica; antes, seria um país de outra classe no sistema internacional: sujeito, e não objeto.

\section{Considerações finais}

O Paraguai enfrenta graves problemas sociais ocasionados pela concentração de renda e economia baseada na exploração agrícola concentrada. As baixas tarifas de impostos nunca

\footnotetext{
6 Indicadores Econômicos consolidados do Banco Central do Brasil. Disponível em:
} http://www.bcb.gov.br/pec/Indeco/Port/indeco.asp, último acesso em 14 de março de 2017. 
foram eficientes para atrair indústrias ao país, principalmente em razão da sua infraestrutura ineficiente. No campo, há poucos empregos, o que força a migração interna em função da especulação imobiliária ou de falta de oportunidades de renda.

No caso paraguaio, a baixa carga tributária, que torna a nação interessante para investidores estrangeiros, não consegue fornecer uma receita tributária suficiente para a implantação de um programa eficiente de desenvolvimento social e de infraestrutura. Limitando-se a exportar bens primários a países mais desenvolvidos, o Paraguai não consegue fazer com que essas divisas sejam redistribuídas, formando uma minoria muito rica enquanto a maior parte da população vive com até 1,5 salário mínimo.

Enquanto grandes produtores pagam impostos irrisórios para exportar a produção, não há políticas públicas para incentivar pequenos agricultores, que sofrem com falta de créditos e incentivos à produção, sem poder concorrer com latifundiários.

Os números da economia paraguaia são relativamente bons, levando em conta o fato de ser um país agrário, pouco industrializado, que depende totalmente das exportações tanto agrícolas quanto de reexportações. Porém, a realidade da população está longe da bonança apresentada pelos números, especialmente no campo.

Quanto ao Brasil, a performance econômica nos primeiros anos da década de 2000 sugeriu que o país estaria numa outra frente no contexto internacional. No entanto, o país foi beneficiado pelo boom das commodities, o que facilitou a obtenção de resultados mais robustos e a maior projeção internacional, indicando, inclusive, que este novo momento marcaria a entrada de um novo ator na política global. No entanto, em que pese as análises que apontavam que o Brasil trilhava um rumo certo, como a de Fareed Zakaria, em O Mundo Pós-Americano, e de José Luis Fiori, no ensaio De volta à geopolítica das nações, a conjuntura internacional a partir da crise econômica de 2008 tornou-se mais hostil, em primeiro plano aos países ricos, e, num segundo momento, para as nações mais frágeis. Com efeito, imaginava-se que essa dicotomia estava superada não necessariamente pelas benesses da globalização, tal qual pensada no ideário assimilado a partir do Consenso de Washington, mas, sim, a partir do desempenho objetivo das economias de países como Brasil, cujo crescimento chamou a atenção de analistas, da mídia e mesmo de países centrais.

Ocorre que, a despeito daquele momento, as economias periféricas continuam dependentes do cenário internacional, que, por sua vez, é controlado pelos países que estão no centro do sistema. Em outras palavras, na medida em que a economia global ainda obedece aos interesses e ao consenso forjado pelos países centrais, não há espaço para que as nações periféricas possam sair da condição subalterna atendendo as regras do jogo, tais como estão 

e-ISSN 2016/Atual: 2525-7870 | e-ISSN 2015/2016: 2447-018X

postas. No limite, Brasil e Paraguai tendem a avançar apenas quando houver a chancela dos países que controlam a dinâmica do capitalismo internacional. O centro permanece distante para a periferia.

\section{Referências}

ALCARAZ, José Nicolas Morinígo. Auge de la producción rural y crisis campesina. Asunción: Fondo Nacional de la Cultura y las Artes, 2009.

ARCE, Lucas. Tendiendo costosos puentes: Paraguay en el Mercosur. Civitas - Revista de Ciências Sociais. Pontifícia Universidade Católica do Rio Grande do Sul. vol. 10, núm. 1, p. 118-133, Porto Alegre, 2010.

BANCO CENTRAL DO BRASIL. Indicadores Econômicos consolidados. Disponível em: <http://www.bcb.gov.br/pec/Indeco/Port/indeco.asp>, último acesso em 14 mar 2017.

BANCO MUNDIAL. Índice de Gini. Disponível em: <http://datos.bancomundial.org/indicador /SI.POV.GINI?locations=PY\&view=chart>. Acesso em: 22 fev. 2017

BORDA, Dionisio; MASI, Fernando. Paraguay. Estancamiento económico y desgaste político en los años del Mercosur. In: BOUZAS, Roberto (Org.). Realidades nacionales comparadas. Buenos Aires: Grupo Editor Altamira, 2002. p. 145-248.

CENTRO DE ANÁLISIS Y DIFUSIÓN DE LA ECONOMÍA PARAGUAYA (Cadep). Observatorio de Economía Internacional. Informe de Comercio Exterior 2015-2016. Disponível em <http://www.cadep.org.py/uploads/2016/02/Informe-Especial-Comercio-Exterior-2015ADAPTADO.pdf >. Acesso em 22 fev. 2017.

COMISIÓN ECONÓMICA PARA AMÉRICA LATINA Y EL CARIBE (CEPAL). Estudio Económico de América Latina y el Caribe - 2016: Brasil. 9 p. 2016a. Disponível em <http://repositorio.cepal.org/bitstream/handle/11362/40326/72/1600548EE_Brasil_es.pdf >. Acesso em: 22 jan. 2017

. Estudio Económico de América Latina y el Caribe - 2016: Paraguay. 9 p. 2016b Disponível em <http://repositorio.cepal.org/bitstream/handle/11362/40326/122/1600548EE_Paraguay_es.pdf>. Acesso em: 22 jan. 2017

DIRECCIÓN GENERAL DE ESTADÍSTICA, ENCUESTAS Y CENSOS (DGEEC). Principales Resultados de la Encuesta Permanente de Hogares EPH 2015. Fernando de la Mora: DGEEC, 2015. 151 p. Disponível em: <http://www.dgeec.gov.py/Publicaciones/Biblioteca/eph-2015/PRINCIPALES \%20RESULT ADOS\%20EPH\%202015.pdf>. Acesso em 12 jan. 2017.

FIORI, José Luis. O Poder Global. São Paulo: Boitempo, 2007.

FOGEL. Ramón. Estructura Social y Procesos Políticos. Asunción: Servilibro, 2005.

FURTADO, Celso. Obra autobiográfica. São Paulo: Companhia das Letras, 2014.

GULLO, Marcelo. A insubordinação fundadora. Florianópolis: Insular, 2005.

HANRATTY, Dennis Michael; MEDITZ, Sandra W. Paraguay: A Country Study. Washington, D.C.: Federal Research Division, Library of Congress: For sale by the Supt. of Docs., U.S. G.P.O, 1990. Disponível em: <https://www.loc.gov/item/89600299/> Acesso em 22 jan. 2017. 

e-ISSN 2016/Atual: 2525-7870 | e-ISSN 2015/2016: 2447-018X

INSTITUTO BRASILEIRO DE GEOGRAFIA E ESTATÍSTICA (IBGE). Pesquisa Mensal de Emprego. Tabelas completas. Disponível em: <http://www.ibge.gov.br/home/estatistica/ indicadores/trabalhoerendimento/pme_nova/defaulttab_hist.shtm>. Acesso em 27 jan. 2017 LANDER, Edgardo (org.) La Colonialidad del saber: eurocentrismo y ciencias sociales. Buenos Aires: Fundación CICCUS, 2016.

LIMA, MJO. Os processos de modernização das organizações empresarias. Disponível em: <http://books.scielo.org/id/cbyx4/pdf/lima-9788579830372-02.pdf>. Acesso em 13 mar. 2017 PRADO JÚNIOR, Caio. A questão agrária. São Paulo: Brasilense, 1981.

SCHUSTER, Caroline E. Social collateral: woman and microfinance in Paraguay's smuggling economy. Oakland: University of California Press, 2015.

SILVA, José Graziano da. A Nova Dinâmica da Agricultura Brasileira. Campinas: Unicamp: 1998.

TAVARES, Maria da Conceição. Auge e declínio do processo de substituição de importações no Brasil. IN: - v.1, p. 217-237

THE HERITAGE FOUNDATION. Index of economic freedom 2016. Disponível em <http://www.heritage.org/index/country/paraguay>. Acesso em 22 jan. 2017.

UNESCO. Institute for Statistics. Education: Expenditure on education as \% of GDP (from government sources). Disponível em: <http://data.uis.unesco.org/Index.aspx?DataSetCode= EDULIT_DS\&popupcustomise=true\&lang=en\#>. Acesso em: 12 out. 2016.

UNITED NATIONS DEVELOPMENT PROGRAMME - UNDP. Human Development Report 2016. Disponível em: < http://hdr.undp.org/en/countries/profiles/PRY >. Acesso em 22 out. 2016

UNITED STATES DEPARTMENT OF AGRICULTURE (USDA). Foreign Agricultural Service. Brasil: Oilseeds and Products Update. Global Agricultural Information Network: 2017. 4p. Disponível em: <https://gain.fas.usda.gov/Recent\%20GAIN\%20Publications/Oilseeds\%20and\%20Products\%20U pdate_Brasilia_Brazil_12-28-2016.pdf>. Acesso em: 22 jan. 2017.

Oilseeds: World Markets and Trade. Global Agricultural Information Network 2016a. 37p. Disponível em: <http://usda.mannlib.cornell.edu/usda/fas/oilseed-trade//2010s/ 2016/oilseed-trade-1012-2016.pdf>. Acesso em: 22 jan. 2017.

Paraguay: Oilseeds and Products Annual. Global Agricultural Information Network: 2016b. 9p. Disponível em: <http://gain.fas.usda.gov/Recent\%20GAIN\%20Publications/Oilseeds\%20and\%20 Products\%20Annual_Buenos\%20Aires_Paraguay_4-17-2016.pdf >. Acesso em: 22 jan. 2017.

ZAKARIA, Fareed. O Mundo Pós-Americano. São Paulo: Companhia das Letras, 2008. 